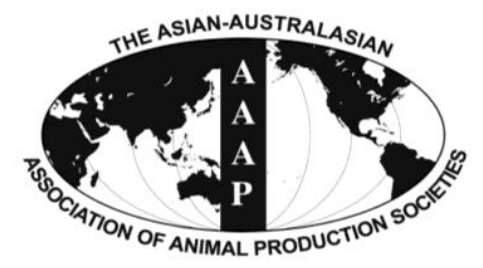

Asian Australas. J. Anim. Sci.

Vol. 26, No. 11 : 1592-1597 November 2013

http://dx.doi.org/10.5713/ajas.2013.13178

www.ajas.info

pISSN 1011-2367 elSSN 1976-5517

\title{
Effect of Bacillus Subtilis-based Direct-fed Microbials on Immune Status in Broiler Chickens Raised on Fresh or Used Litter
}

\author{
K. W. Lee, H. S. Lillehoj*, S. I. Jang, S. H. Lee, D. A. Bautista ${ }^{1}$, and G. R. Siragusa ${ }^{2}$ \\ Animal Biosciences and Biotechnology Laboratory, Beltsville Agricultural Research Center, \\ Agricultural Research Service, USDA, Beltsville, MD 20705, USA
}

\begin{abstract}
Type of dietary direct-fed microbials (DFMs) or poultry litter could directly influence the composition of gut microbiota. Gut microbiota plays an important role in shaping the developing immune system and maintaining the homeostasis of the mature immune system in mammal and chickens. The present study was carried out to investigate the interaction among litter, DFMs and immunity in broiler chickens exposed to a field-simulated environment. Immune status of broiler chickens was assessed by serum antibodies against Eimeria spp. and Clostridium spp. and intestinal cytokine mRNA expression. The current experimental design had a 3 $\times 2$ factorial arrangement of treatments with three types of litter, i.e., fresh litter or used litter that was obtained from a farm with no disease outbreak (used litter) or a farm with history of a gangrenous dermatitis outbreak (GD litter), and two dietary treatments with or without DFMs. It was found that either DFM addition or type of litter significantly affected anticoccidial antibody levels of broiler chickens at $\mathrm{d}$ 42. In general, dietary DFMs increased the anticoccidial antibodies in the fresh-litter raised chickens, but lowered the levels in the GD-litter raised chickens. Serum antibodies against Clostridium perfringens $\alpha$-toxin were significantly $(p<0.05)$ higher in chickens raised on GD litter compared with those raised on fresh litter. Cytokine mRNA expression was significantly $(\mathrm{p}<0.05)$ altered by either the type of litter or DFMs. Of interest, dietary DFMs lowered interferon- $\gamma$, interleukin 1beta, and CXCLi2 cytokine mRNA expression in chickens raised on fresh litter but increased them in GD-litter raised chickens. In conclusion, dietary DFMs modulate various immune parameters of broiler chickens, but the DFM-mediated effects were dependent upon the type of litter on which chickens were raised. (Key Words: Direct-fed Microbials, Cytokines, Broiler Chickens, Used Litter, Immunity)
\end{abstract}

\section{INTRODUCTION}

In the modern intensive production environment, multiple broiler flocks are commonly raised on a single batch of litter where day-old chickens are placed directly on used litter (Volkova et al., 2009). Litter is mainly composed of the bedding materials, feather, manure, the spilt feed and microbiota. Bolan et al. (2010) stated that microbial populations in poultry litter can exceed $10^{10}$ cells per $\mathrm{g}$ of litter and gram positive bacteria account for almost $90 \%$ of the microbial diversity. It is suggested that poultry litter provides stable environment for newly-placed chickens for colonizing adult-type microbiota (Torok et al., 2009;

\footnotetext{
* Corresponding Author: Hyun S. Lillehoj. Tel: +1-301-504-8771, Fax: +1-301-504-5103, E-mail: Hyun.Lillehoj@ARS.USDA.GOV

${ }^{1}$ Lasher Poultry Diagnostic Laboratory, University of Delaware, Georgetown, DE 16483, USA.

${ }^{2}$ Danisco, W227 N752 Westmound Drive, Waukesha, WI 53186, USA.

Submitted Mar. 28, 2013; Accepted May 6, 2013; Revised Jun. 18, 2013
}

Cressman et al., 2010). In contrary, it also acts as a reservoir for several pathogens including Eimeria spp., Salmonella spp., Clostridium perfringens, Campylobacter jejuni, and Escherichia coli (Bolan et al., 2010; Chinivasagam et al., 2010; Lee et al., 2012b). In addition to the interrelation between the type of litter and gut microbiota (Torok et al., 2009; Cressman et al., 2010), we have recently reported the influence of fresh or used litter on the development of immune systems in broiler chickens (Lee et al., 2011), highlighting close interplay between the quality of litter used during chicken growth and the development of immune cells.

Direct-fed microbials (DFMs) are beneficial live microorganisms which when administered in adequate amounts confer a health benefit on the host by balancing its intestinal microbes (FAO/WHO, 2002). Although the concept of DFMs is not new, it has been recently gained much attention as a prophylactic agent against bacterial diseases presumably either by balancing gut microbiota, or by modulating host immunity, or both (Callaway et al., 
2008). In our laboratory, DFM-based immunomodulation as an alternative coccidiosis control strategy has been documented (Lee et al., 2010c). For example, it has been shown that dietary Bacillus subtilis-based DFMs reduced the clinical signs of experimental avian coccidiosis with concomitant increase in protective immunity in broiler chickens (Lee et al., 2010a). In addition, Bacillus-based DFMs modulated various parameters of inflammation, and humoral and cellular immunities in broiler chickens (Lee et al., 2010b). It may be that primary modes of action by DFMs are balancing gut microbiota community and/or modulating host immunity (Flint and Garner, 2009; Applegate et al., 2010; Lee et al., 2010c), presumably acting singly or in combination.

In this study, we examined the interaction of two factors, i.e., type of litter (fresh vs used) and dietary DFMs, which are considered driving forces affecting gut microbiota and immune responses.

\section{MATERIALS AND METHODS}

\section{Experimental design}

The experiment was conducted at the University of Delaware research facility. The experiment had a $3 \times 2$ factorial arrangement of 3 litter treatments with fresh or used litter and two dietary regimens with or without DFMs. Used litter was obtained from two different broiler farms with (GD litter) or without (used litter) a history of gangrenous dermatitis (GD), where at least 10 broiler flocks had already been grown. Our previous study showed that GD typically occurs at 4 to 7 weeks of age in broiler chickens and is associated with $C$. perfringens and $C$. septicum (Li et al., 2010a,b). In the US, GD is one emerging disease of concern and it has been proposed that disrupted gut microbiota may play a role in the development of field GD infection (Ritter, 2006; Dumas et al., 2011). The fresh wood shavings were used as the fresh litter.

Basal diet was a nonmedicated mash-type diet consisting of corn, soybean meal, poultry and animal byproducts, and distiller's dried grains soluble. The experimental DFM diet was formulated by mixing the basal diet with commercially available DFMs (Avicorr, Danisco/Agtech Products Inc., Waukesha, WI) to contain $150,000 \mathrm{cfu}$ per gram of diet as the manufacturer recommended. Control diet was formulated by mixing the base diet with carrier only.

One hundred fifty 1-d-old broiler chickens (Ross breed) were used in this study. All broiler chickens used in this study had received normal vaccinations including Marek's disease (turkey herpes virus (HVT), SB-1 and Rispen) in ovo at $18 \mathrm{~d}$ of incubation, and Newcastle disease (ND) and infectious bronchitis (IB) via coarse spray after hatch at the local hatchery. Upon arrival, they were vaccinated orally with Pfizer Inovocox vaccine, randomly placed $(\mathrm{n}=$ 25/group) on fresh, used, or GD litter, and fed a diet containing DFM-enriched or DFM-free diet. Diet and water were provided ad libitum basis. All experimental protocols were approved by the Small Animal Care Committee of Beltsville Agricultural Research Center and the University of Delaware.

\section{Sampling}

At d 14, 28, and 42, five birds from each group were randomly sampled for blood after euthanasia. Sera were obtained by gentle centrifugation and stored at $-20^{\circ} \mathrm{C}$ until use. For measurement of cytokine mRNA expression levels, 5-cm segments from mid-jejunum and -ileum were sampled and used for RNA isolation.

\section{Serum antibodies against Eimeria spp. or $C$. perfringens}

Serum antibodies against Eimeria spp. and $C$. perfringens were measured by in-house ELISA using recombinant coccidia EtMIC2 (Lillehoj et al., 2005) and $C$. perfringens $\alpha$-toxin proteins (Lee et al., 2012a). The EtMIC2 gene was originally cloned from E. tenella and known to encode a microneme adhesion involved in parasite motility and host cell invasion by the parasite (Lillehoj et al. 2005). $\alpha$-Toxin, a zinc metalloenzyme with phospholipase, sphingomyelinase, and hemolytic activities, is produced by $C$. perfringens strains and is a major virulence factor of the pathogen (Lee et al., 2012a). In brief, 96-well microtiter plates were coated overnight with 1 $\mu \mathrm{g} /$ well of purified recombinant proteins. The plates were washed with PBS containing $0.05 \%$ Tween (PBS-T), and blocked with PBS containing 1\% BSA for $1 \mathrm{~h}$ at room temperature. Then, diluted serum samples were added (100 $\mu \mathrm{L} /$ well), incubated with gentle agitation for $2 \mathrm{~h}$ at room temperature, and washed with PBS-T. Bound antibodies were then detected with peroxidase-conjugated rabbit antichicken IgY (Sigma, St. Louis, MO) and peroxidase specific substrates. A value of $\mathrm{OD}_{450}$ was determined with a microplate reader (Bio-Rad, Richmond, CA).

\section{Cytokine mRNA assay}

Total RNA was extracted from intestine using TRIzol (Invitrogen) as described (Hong et al., 2006; Park et al., 2008). Five micrograms of total RNA were treated with 1.0 $\mathrm{U}$ of DNase I and $1.0 \mu \mathrm{L}$ of $10 \times$ reaction buffer (Sigma), incubated for $15 \mathrm{~min}$ at room temperature, $1.0 \mu \mathrm{L}$ of stop solution was added, and the mixture was heated at $70^{\circ} \mathrm{C}$ for 10 min. RNA was reverse transcribed using the StrataScript first-strand synthesis system (Stratagene, La Jolla, CA) according to the manufacturer's recommendations. Quantitative RT-PCR oligonucleotide primers for chicken 
Table 1. Oligonucleotide primers used for quantitative RT-PCR of chicken cytokines

\begin{tabular}{|c|c|c|c|c|}
\hline Type & RNA target ${ }^{1}$ & Primer sequences ${ }^{2}$ & $\begin{array}{l}\text { PCR product size } \\
\text { (bp) }\end{array}$ & Genbank accession no. \\
\hline Reference & GAPDH & $\begin{array}{l}\text { F: 5'-GGTGGTGCTAAGCGTGTTAT-3' } \\
\text { R: 5'-ACCTCTGTCATCTCTCCACA-3' }\end{array}$ & 264 & K01458 \\
\hline Proinflammatory & IL1 $\beta$ & $\begin{array}{l}\text { F: 5'-TCTGGGACCACTGTATGCTCT-3', } \\
\text { R: 5'-ACACCAGTGGGAAACAGTATCA-3, }\end{array}$ & 256 & AF000631 \\
\hline Th-1 & $\mathrm{IFN} \gamma$ & $\begin{array}{l}\text { F: 5'-AGCTGACGGTGGACCTATTATT-3' } \\
\text { R: 5'-GGCTTTGCGCTGGATTC-3' }\end{array}$ & 259 & Y07922 \\
\hline Th-2 & IL10 & $\begin{array}{l}\text { F: 5'-CGGGAGCTGAGGGTGAA-3' } \\
\text { R: 5'-GTGAAGAAGCGGTGACAGC-3' }\end{array}$ & 272 & AJ621614 \\
\hline Chemokine & CXCLi2 & $\begin{array}{l}\text { F: 5'-GGCTTGCTAGGGGAAATGA-3' } \\
\text { R: 5'-AGCTGACTCTGACTAGGAAACTGT-3, }\end{array}$ & 200 & AJ009800 \\
\hline
\end{tabular}

${ }^{1}$ GAPDH = Glyceraldehyde 3-phosphate dehydrogenase; IL = Interleukin; IFN = Interferon.

${ }^{2} \mathrm{~F}=$ Forward primer; $\mathrm{R}=$ Reverse primer.

cytokines, chemokines, and GAPDH are listed in Table 1. Amplification and detection were carried out using equivalent amounts of total RNA from intestine using the Mx3000P system and Brilliant SYBR Green QPCR master mix (Stratagene) as described (Hong et al., 2006; Park et al., 2008). Standard curves were generated using $\log _{10}$ diluted standard RNA and the levels of individual transcripts were normalized to those of GAPDH using the Q-gene program (Muller et al., 2002). Each analysis was performed in triplicate. To normalize RNA levels between samples within an experiment, the mean threshold cycle $\left(\mathrm{C}_{\mathrm{t}}\right)$ values for the amplification products was calculated by pooling values from all samples in that experiment.

\section{Statistical analysis}

The data were evaluated by two-way ANOVA using the program SPSS 15.0 for Windows (SPSS Inc., Chicago, IL), with litter type and DFMs as main factors. The individual chicken was considered as the experimental unit. Treatment means for type of litter were tested for statistically significant differences using Duncan's multiple range test in SPSS 15.0 for Windows. A value of $\mathrm{p}<0.05$ was considered significant.

\section{RESULTS}

\section{Antibody levels against Eimeria and $C$. perfringens}

Anti-EtMIC2-specific antibody levels were not affected ( $>0.05$ ) by any of treatments at d 14 and 28 (Table 2). On the other hand, chickens raised on the GD litter exhibited highest $(\mathrm{p}<0.05)$ serum antibody titers to Eimeria compared with those raised on fresh or used litter at $d 42$. Dietary DFMs significantly $(\mathrm{p}<0.05)$ reduced antibody levels at $d$ 42. Significant interaction between DFMs and litter type on antibody levels was detected at d 42, i.e., dietary DFMs raised the antibody levels when chickens were raised on fresh litter while lowered the levels when chickens were raised on GD litter.
In this study, serum antibodies to $C$. perfringens $\alpha$-toxin, were affected by the type of litter $(p<0.05)$, i.e., birds grown on GD litter had elevated antibody levels compared with those grown on fresh or used litter, especially at d 14 and 42 (Table 3). DFM did not have any effects on clostridial antibody levels, nor interacted with the type of litter. Although substantial amounts of antibodies against Eimeria spp. or $C$. perfringens $\alpha$-toxin were detected, Eimeria- or $C$. perfringens-associated gut lesions were not observed upon

Table 2. Effects of type of litter and direct-fed microbials (DFMs) on serum EtMIC2-specific antibody levels in broiler chickens ${ }^{1}$

\begin{tabular}{lcccc}
\hline \multirow{2}{*}{ Litter type } & \multirow{2}{*}{ DFM } & \multicolumn{3}{c}{ EtMIC2 } \\
\cline { 2 - 5 } Fresh & - & 0.30 & 0.58 & 0.78 \\
& + & 0.35 & 0.57 & 1.07 \\
Used & - & 0.37 & 0.68 & 0.83 \\
& + & 0.29 & 0.60 & 0.73 \\
GD $^{2}$ & - & 0.51 & 0.59 & 1.52 \\
& + & 0.34 & 0.65 & 0.82 \\
Pooled SEM & & 0.05 & 0.08 & 0.05 \\
Main effect means & & & & \\
$\quad$ Litter & & & & \\
$\quad$ Fresh & & 0.32 & 0.57 & $0.92^{\mathrm{b}}$ \\
$\quad$ Used & & 0.33 & 0.64 & $0.77^{\mathrm{c}}$ \\
$\quad$ GD & & 0.42 & 0.62 & $1.17^{\mathrm{a}}$ \\
DFM & & & & \\
$\quad-$ & & & & \\
$\quad+$ & & 0.39 & 0.62 & $1.05^{\mathrm{a}}$ \\
Source of variation & & -0.33 & 0.61 & $0.87^{\mathrm{b}}$ \\
Litter & & 0.107 & 0.756 & 0.001 \\
DFM & & 0.134 & 0.929 & 0.001 \\
Litter×DFM & & 0.144 & 0.772 & 0.001 \\
\hline
\end{tabular}

$\overline{\mathrm{a}, \mathrm{b}, \mathrm{c}}$ Means in the same column within the same factor not sharing a common superscript are significantly different $(\mathrm{p}<0.05)$

${ }^{1}$ Each value represents the mean optical density $( \pm \mathrm{SD})$ of five birds per treatment $(\mathrm{n}=5)$.

${ }^{2} \mathrm{GD}=$ Gangrenous dermatitis.

${ }^{3} \mathrm{SEM}=$ Standard error of the mean 
Table 3. Effects of type of litter and direct-fed microbials (DFMs) on serum Clostridium perfringens $\alpha$-toxin-specific antibody levels in broiler chickens ${ }^{1}$



necropsy.

\section{Cytokine mRNA transcripts}

Effect of litter type on cytokine mRNA expression was clearly observed. Especially, birds raised on GD litter had lowest $(\mathrm{p}<0.05)$ levels of cytokine interferon (IFN) $\gamma$, interleukin (IL) $1 \beta$, and IL10 transcripts compared with those raised on fresh litter. DFM-fed birds had increased IFN $\gamma$ transcripts $(p<0.05)$ compared with birds fed DFMfree diet (Figure 1). Significant interaction between the type of litter and DFMs was observed with IL1 $\beta$, IFN $\gamma$, and CXCLi2 transcripts. Of note, birds fed DFM diet and raised on fresh litter lowered the levels of IL1 $\beta$, IFN $\gamma$, and CXCLi2 transcripts compared with those fed DFM-free diet and raised on fresh litter. In contrast, birds fed DFM diet and raised on GD litter increased IL1 $\beta$, IFN $\gamma$, and CXCLi2 mRNAs compared with those fed DFM-free diet and raised on GD litter.

\section{DISCUSSION}

It is well documented that dietary DFMs modulate various aspects of immunity in broiler chickens (Lee et al., 2010a,b,c). Also, we have recently reported that the exposure of growing chickens to used poultry litter stimulated humoral and cell-mediated immune responses, presumably due to contact with contaminating enteric pathogens (Lee et al., 2011). Given that dietary DFM or the type of litter influences host immunity, their interaction on developing post-hatch immunity is expected. However, to our knowledge, those expectations have never been answered. Thus, the present study was conducted to investigate whether dietary DFMs modulate immune response, with respect to humoral antibody response to Clostriium and Eimeria, and cell-mediated immunity as measured by cytokine production in broiler chickens raised on fresh, used or GD litter.

In this study, higher serum antibodies against Eimeria or C. perfringens were observed in chickens raised on GD litter compared with those on the fresh or used litter, indicating that GD litter served as a consistent source of antigenic exposure to Eimeria spp. and $C$. perfringens. Interestingly, dietary supplementation with DFMs ( $B$. subtilis) significantly lowered Eimeria-specific antibodies, but did not lower serum antibodies against $C$. perfringens $\alpha$-toxins. There was significant interaction between DFMs and the type of litter on Eimeria-specific antibody levels. Our result indicates that dietary DFMs modulate postinfection humoral antibody response in chickens exposed to naturally infected litter, albeit that the exact mechanisms are not available at this time.

As to cytokine response, broiler chickens raised on GD litter showed significantly decreased expression levels of IL1 $\beta$, IFN $\gamma$, and IL10 compared with those raised on the fresh litter. Broiler chickens raised on used litter exhibited significant decrease in IL1 $\beta$ transcripts compared with the fresh litter-raised chickens. Putatively, these observations on the reduced expression of the cytokines may reflect overall immune-suppression, especially in broiler chickens raised on GD litter. An earlier study found that GD-afflicted broiler chickens demonstrated reduced expression potentials of most cytokines in skin or gut tissues compared with the GD-free healthy chickens (Li et al., 2010b). Contrary to our study, Shanmugasundaram et al. (2012) reported that broiler chickens raised on used litter had an increase in IL1 $\beta$ and IL4 transcripts, but a decrease in IL10 transcripts in cecal tonsils compared with those raised on fresh litter. Different cytokine levels seen in these two studies may reflect different genetic background of chickens, age of chickens, gut commensals, and other environmental factors such as diets and litter contaminants. Especially, the latter study suggested that higher IL1 $\beta$ mRNA expression was indicative to a low level of chronic inflammation in the cecal tonsil that was exposed to pathogenic or nonpathogenic bacteria. Furthermore, we sampled mid-intestine of 28-d-old chickens raised on litter where 10 broiler flocks had already been grown while Shanmugasundaram et al. 

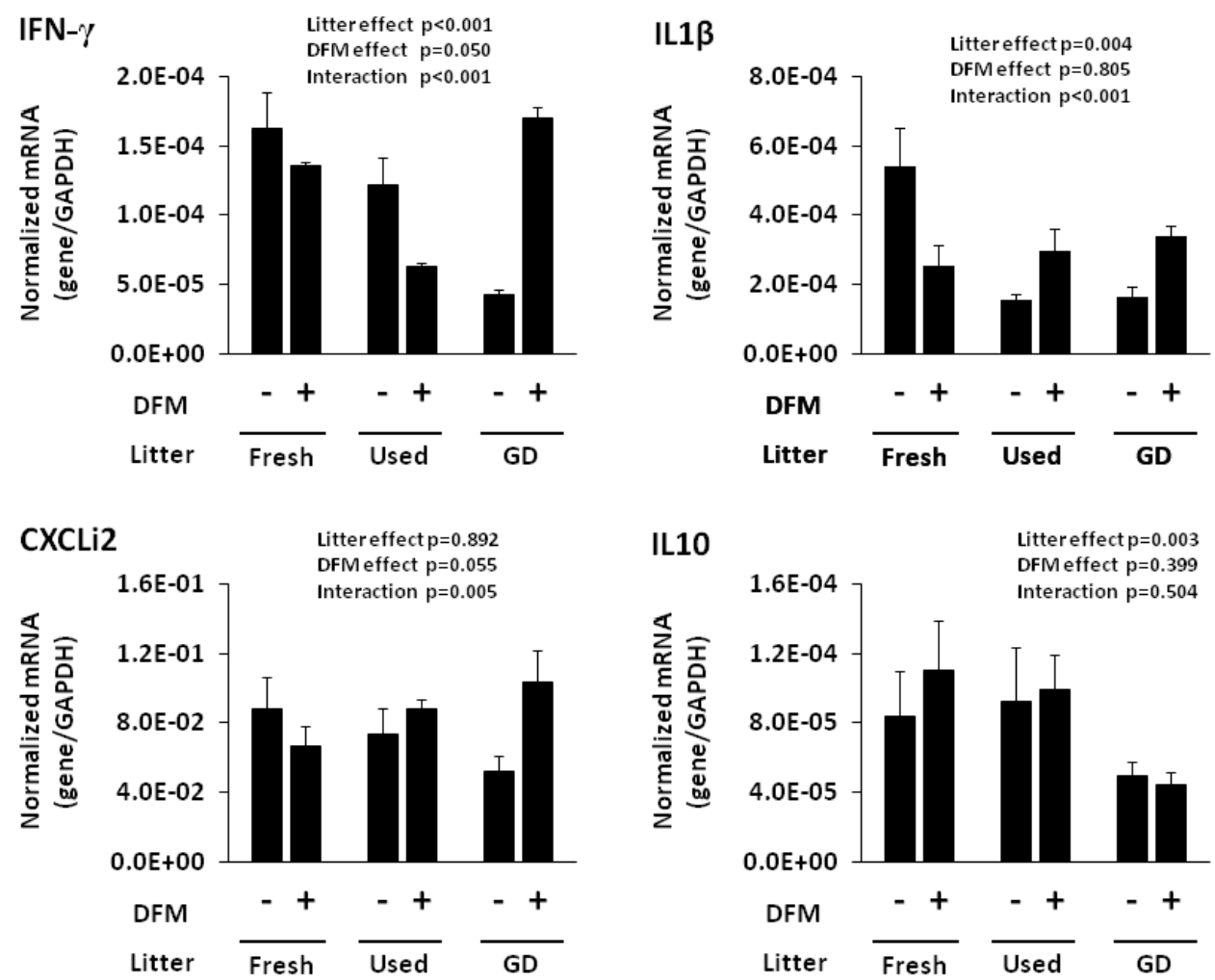

Figure 1. Effect of type of litter and direct-fed microbials (DFMs) on intestinal cytokine transcript levels in broiler chickens. Chickens were fed either DFM-enriched or DFM-free diets, and raised on fresh or used litter. Used litter was obtained from no disease outbreak farm (used litter) or a farm with histories of gangrenous dermatitis (GD litter). At $28 \mathrm{~d}$ post-hatch, intestinal tissues were removed and the level of transcript for IL1 $\beta$, IFN $\gamma$, IL10, CXCLi2 and GAPDH were quantified by quantitative RT-PCR. Values were expressed as mean $( \pm \mathrm{SD})$ of three replicates per treatment and evaluated by two-way ANOVA with type of litter and DFMs as main factors. A value of $\mathrm{p}<0.05$ was considered significant.

(2012) sampled cecal tonsils of 10- or 35-d-old chickens raised on litter where 3 broiler flocks had been grown. In any event, further studies are needed to clarify the discrepancy.

Dietary DFMs moderately increased the expression patterns of IL1 $\beta$, IFN $\gamma$, and CXCLi2 in chickens raised on GD litter, but decreased those expression patterns in chickens raised on fresh litter. In addition, dietary DFMs increased IL1 $\beta$, but lowered IFN $\gamma$ transcripts in chickens raised on used litter. Overall, significant interaction between DFM and type of litter on cytokine response was observed. It is well known that dietary DFMs can modulate various aspects of innate and acquired immunity in broiler chickens (Lee et al., 2010a,c). Our study clearly shows that dietary DFMs alter cell-mediated immunity in terms of cytokine responses in chickens raised on the different types of litter. The underlying immunomodulatory mechanism(s) by dietary DFMs is clearly linked to the DFM-mediated shift in gut microbiota (Neumann et al., 2011a,b) or type of litter used (Cressman et al., 2010; Neumann et al., 2011b).

In conclusion, the present study demonstrated how the type of litter and dietary DFMs influence host immune response to pathogens, especially antibodies against Eimeria spp. or Clostridium spp., and cytokine mRNA expression, in commercially raised broiler chickens. This is the first study showing clear association among the type of litter, dietary DFMs, and host immunity. Collectively, our study provides clear evidence that dietary DFMs possess the counteracting, immune-modulating properties in broiler chickens that are exposed to different types of litter.

\section{ACKNOWLEDGEMENTS}

This project was supported by a Trust agreement established between ARS-USDA and Danisco and partially by the ARS in-house project 1245-32000-097-00. We thank Marjorie Nichols and Stacy O'Donnell for their technical assistances.

\section{REFERENCES}

Applegate, T. J., V. Klose, T. Steiner, A. Ganner, and G. Schatzmayr. 2010. Probiotics and phytogenics for poultry: Myth or reality? J. Appl. Poult. Res. 19:194-210.

Bolan, N. S., A. A. Szogi, T. Chuasavathi, B. Seshadri, M. J. 
Rothrock, and P. Panneerselvam. 2010. Uses and management of poultry litter. World's Poult. Sci. J. 66:673-698.

Callaway, T. R., T. S. Edrington, R. C. Anderson, R. B. Harvey, K. J. Genovese, C. N. Kennedy, D. W. Venn, and D. J. Nisbet. 2008. Probiotics, prebiotics and competitive exclusion for prophylaxis against bacterial disease. Anim. Health Res. Rev. 9:217-225.

Chinivasagam, H. N., M. Redding, G. Runge, and P. J. Blackall. 2010. Presence and incidence of food-borne pathogens in Australian chicken litter. Br. Poult. Sci. 51:311-318.

Cressman, M. D., Z. Yu, M. C. Nelson, S. J. Moeller, M. S. Lilburn, and H. N. Zerby. 2010. Interrelations between the microbiotas in the litter and in the intestines of commercial broiler chickens. Appl. Environ. Microbiol. 76:6572-6582.

Dumas, M. D., S. W. Polson, D. Ritter, J. Ravel, J. Gelb, R. Morgan, and K. E. Wommack. 2011. Impacts of poultry house environment on poultry litter bacterial community composition. PLoS ONE 6:e24785.

FAO/WHO. 2002. Guidelines for the evaluation of probiotics in food. Joint FAO/WHO Working Group Report on Drafting Guidelines for the Evaluation of Probiotics in Food. Ontario, Canada.

Flint, J. F. and M. R. Garner. 2009. Feeding beneficial bacteria: A natural solution for increasing efficiency and decreasing pathogens in animal agriculture. J. Appl. Poult. Res. 18:367378.

Hong, Y. H., H. S. Lillehoj, E. P. Lillehoj, and S. H. Lee. 2006. Changes in immune-related gene expression and intestinal lymphocyte subpopulations following Eimeria maxima infection of chickens. Vet. Immunol. Immunopathol. 114:259272.

Lee, K. W., H. S. Lillehoj, S. I. Jang, G. Li, S. H. Lee, E. P. Lillehoj, and G. R. Siragusa. 2010a. Effect of Bacillus-based direct-fed microbials on Eimeria maxima infection in broiler chickens. Comp. Immunol. Microbiol. Infect. Dis. 33:e105e110.

Lee, K. W., S. H. Lee, H. S. Lillehoj, G. X. Li, S. I. Jang, U. S. Babu, M. S. Park, D. K. Kim, E. P. Lillehoj, A. P. Neumann, T. G. Rehberger, and G. R. Siragusa. 2010b. Effects of direct-fed microbials on growth performance, gut morphometry, and immune characteristics in broiler chickens. Poult. Sci. 89:203216

Lee, K. W., H. S. Lillehoj, and G. R. Siragusa. 2010c. Direct-fed microbials and their impact on the intestinal microflora and immune system of chickens. J. Poult. Sci. 47:106-114.

Lee, K. W., H. S. Lillehoj, S. H. Lee, S. I. Jang, G. D. Ritter, D. A. Bautista, and E. P. Lillehoj. 2011. Impact of fresh or used litter on the post-hatch immune system of commercial broilers. Avian Dis. 55:539-544.

Lee, K. W., H. S. Lillehoj, M. S. Park, S. I. Jang, G. D. Ritter, Y. H. Hong, W. Jeong, H. Y. Jeoung, D. J. An, and E. P. Lillehoj. 2012a. Clostridium perfringens $\alpha$-toxin and NetB toxin antibodies and their possible role in protection against necrotic enteritis and gangrenous dermatitis in broiler chickens. Avian Dis. $56: 230-233$.
Lee, K. W., H. S. Lillehoj, S. I. Jang, M. Pagès, D. A. Bautista, C. R. Pope, G. D. Ritter, E. P. Lillehoj, A. P. Neumann, and G. R. Siragusa. 2012b. Effects of in ovo vaccination and anticoccidials on the distribution of Eimeria spp. in poultry litter and serum antibody titers against coccidia in broiler chickens raised on the used litters. Res. Vet. Sci. 93:177-182.

Li, G., H. S. Lillehoj, K. W. Lee, S. I. Jang, P. Marc, C. G. Cyril, G. D. Ritter, D. A. Bautista, K. Phillips, A. P. Neumann, T. G. Rehberger, and G. R. Siragusa. 2010a. An outbreak of gangrenous dermatitis in commercial broiler chickens. Avian Pathol. 39:247-253.

Li, G., H. S. Lillehoj, K. W. Lee, S. H. Lee, M. S. Park, S. I. Jang, G. R. Bauchan, C. G. Gay, G. D. Ritter, D. A. Bautista, and G. R Siragusa. 2010b. Immunopathology and cytokine responses in commercial broiler chickens with gangrenous dermatitis. Avian Pathol. 39:255-264.

Lillehoj, H. S., X. Ding, R. A. Dalloul, T. Sato, A. Yasuda, and E. P. Lillehoj. 2005. Embryo vaccination against Eimeria tenella and E. acervulina infections using recombinant proteins and cytokine adjuvants. J. Parasitol. 91:666-673.

Muller, P. Y., H. Janovjak, A. R. Miserez, and Z. Dobbie. 2002. Processing of gene expression data generated by quantitative real-time RT-PCR. Biotechniques 32:1372-1379.

Neumann, A. P., J. A. Benson, K. W. Lee, G. D. Ritter, D. A. Bautista, H. S. Lillehoj, and G. R. Siragusa. 2011a. Microbiological effects of Bacillus-based DFM supplementation in broilers raised on used litter from commercial farms with different disease histories. Poult. Sci. 90 (E-Suppl. 1):120-121(Abst.).

Neumann, A. P., J. A. Benson, K. W. Lee, G. D. Ritter, D. A. Bautista, H. S. Lillehoj, and G. R. Siragusa. 2011b. Intestinal microbiota of broiler chickens administered a Bacillus based DFM and raised on used litter from commercial farms with different disease histories. 2011 Congress on Gastrointestinal Function. Chicago, IL. April 18-20.

Park, S. S., H. S. Lillehoj, P. C. Allen, D. W. Park, S. Fitzcoy, D. A Bautista, and E. P. Lillehoj. 2008. Immunopathology and cytokine responses in broiler chickens coinfected with Eimeria maxima and Clostridium perfringens with the use of an animal model of necrotic enteritis. Avian Dis. 52:14-22.

Ritter, G. 2006. Proposed pathogenesis of gangrenous dermatitis in chickens and attempts at experimental reproduction. In: Proc. from the 41st National Meeting on Poultry Health and Processing, Ocean City, MD.

Shanmugasundaram, R., M. S. Lilburn, and R. K. Selvaraj. 2012. Effect of recycled litter on immune cells in the cecal tonsils of chickens. Poult. Sci. 91:95-100.

Torok, V. A., R. J. Hughes, K. Ophel-Keller, M. Ali, and R. MacAlpine. 2009. Influence of different litter materials on cecal microbiota colonization in broiler chickens. Poult. Sci. 88:2474-2481.

Volkova, V. V., R. H. Bailey, and R. W. Wills. 2009. Salmonella in broiler litter and properties of soil at farm location. PLOS ONE 4:e6403. 